\title{
DIREITO DE FAMÍLIA E SUCESSÕES NO CÓDIGO DE PROCESSO CIVIL/2015: A PRIMAZIA DA MEDIAÇÃO PARA UMA CULTURA DO DIÁLOGO
}

\author{
Mercedes Ferreira de Araújo 1 \\ Afonso Soares De Oliveira Sobrinho ${ }^{2}$
}

\section{RESUMO}

Nosso objetivo é a análise das inovações trazidas pelo novo Código de Processo Civil em relação ao Direito de Família e Sucessões, em especial a mediação de conflitos. Dessa forma, foi realizada uma revisão bibliográfica sobre as relações entre família, sociedade e Estado Democrático de Direito, abrangendo aspectos jurídicos e sociológicos relacionados à moderna teoria do direito processual. Concluímos que as inovações do CPC/2015 são relevantes para o fortalecimento de novas instituições no Estado Democrático de Direito. Destacamos a primazia da mediação com vista a uma cultura do diálogo entre as partes na lide.

Palavras-chave: Direito de Família; Direito Processual Civil; Diálogo; Mediação; Diversidade.

\section{FAMILY LAW AND SUCCESSIONS IN THE CIVIL PROCEDURE CODE/2015: THE PRIMACY OF MEDIATION FOR A CULTURE OF DIALOGUE}

\begin{abstract}
Our objective is the analysis of innovations brought by the new Code of Civil Procedure in relation to Family Law and Succession, in particular the mediation of conflicts. Therefore, a bibliographic review was carried out on the relations between family, society and the Democratic State of Law, covering juridical and sociological aspects related to the modern theory of procedural law. We conclude that the innovations of CPC/2015 are relevant for the strengthening of new institutions in Democratic State of Law. We emphasize the primacy of mediation with a view to a culture of dialogue between the parties in dispute.
\end{abstract}

Keywords: Family Law; Civil Procedural Law; Dialogue; Mediation; Diversity.

\section{INTRODUÇÃO}

O Brasil vivencia uma efervescência de interações sociais. Os valores tradicionais da família no Estado Democrático de Direito com toda a ebulição político-econômica e institucional são rediscutidos a partir das mudanças nas relações socioafetivas com reflexos na concretização de direitos: “[...] O amor é o elemento constitutivo da união estável”. (DIAS, 2004)

Novas demandas e intercorrências no transcurso da história surgem ora como rápido processo de mudanças estruturais e por vezes sem avanços significativos; são esses, enfim,

\footnotetext{
${ }^{1}$ Mestranda em Direito pela Universidade da Amazônia - UNAMA.

${ }^{2}$ Pós-Doutor em Direito pela Faculdade de Direito do Sul de Minas - FDSM. Doutor em Direito pela Faculdade Autônoma de Direito de São Paulo - FADISP. Advogado.
} 
fenômenos comuns presentes nas nações democráticas relacionados a consolidação e às crises causadas pela cultura de massas, denominados: "[...] os aquém e os além dos problemas". (MORIN, 2007, p. 183-184).

O direito de família e sucessões e o direito processual civil se evidenciam; o instituto da família como base para a convivência humana, pontuada por sonhos e anseios, ideais e valores; o processo civil, como instrumento conducente ao equilíbrio e bom termo desse ideário e na satisfação dos interesses em jogo, permeados pelas pressões da vida e a busca por liberdade, igualdade e segurança.

O direito processual civil estabelece a confluência do sistema normativo, fornecendo aos operadores do direito a resolução da variada gama de interesses em jogo. Dessa forma, delimitam-se a natureza das fontes, a eficácia das normas dentro dos fenômenos tempo e espaço, bem como das interpretações normativas possíveis, com foco numa solução consolidada e harmônica.

Assim, o problema de pesquisa está em conhecer os limites e interações entre o direito de família e sucessões e o direito processual civil de uma forma que apresente alternativas que ultrapassem os limites da mera normatização. A busca por mecanismos e alternativas à disposição das partes para a autocomposição dos conflitos, cujo objeto de estudo é a primazia da mediação como mecanismo de solução consensual. Nesse sentido, no direito de família há espaço para a mediação, conforme o $\mathrm{CNJ}^{1}$ :

\begin{abstract}
A Mediação é uma forma de solução de conflitos na qual uma terceira pessoa, neutra e imparcial, facilita o diálogo entre as partes, para que elas construam, com autonomia e solidariedade, a melhor solução para o problema. Em regra, é utilizada em conflitos multidimensionais, ou complexos. A Mediação é um procedimento estruturado, não tem um prazo definido, e pode terminar ou não em acordo, pois as partes têm autonomia para buscar soluções que compatibilizem seus interesses e necessidades. A conciliação é um método utilizado em conflitos mais simples, ou restritos, no qual o terceiro facilitador pode adotar uma posição mais ativa, porém neutra com relação ao conflito e imparcial. É um processo consensual breve, que busca uma efetiva harmonização social e a restauração, dentro dos limites possíveis, da relação social das partes (BRASIL, 2016).
\end{abstract}

\footnotetext{
${ }^{1}$ No dia 3 de maio de 2016, o CNJ lançou o sistema de Mediação Digital que permite acordos, celebrados de forma virtual, de partes do processo que estejam distantes fisicamente, como, por exemplo, entre consumidores e empresas. O sistema facilita a troca de mensagens e informações entre as partes, que podem chegar a uma solução. Esses acordos podem ser homologados pela Justiça, se as partes considerarem necessário. Caso não se chegue a um acordo, uma mediação presencial será marcada e deverá ocorrer nos Centros Judiciários de Solução de Conflitos e Cidadania (Cejuscs), criados pela Resolução CNJ n. 125 (BRASIL, 2016).
} 
A hipótese a se verificar é se as mudanças trazidas pelo novo CPC atendem aos anseios da sociedade, visando facilitar o acesso à justiça, o incentivo às práticas extrajudiciais na resolução de conflitos no âmbito do direito de família e sucessões.

O objetivo deste estudo é ampliar a compreensão sobre algumas das modificações promovidas pelo novo CPC, visto que influenciam o direito de família e sucessões previstos

no Livro IV do Código Civil, em especial a utilização da mediação para resolução de seus conflitos. Dessa forma, o cerne do texto passa pelas questões jurídicas ${ }^{2}$, da ética ${ }^{3}$ e sociologia.

Deve ser sempre lembrado pelo juiz e pelo advogado, bem como pelo membro do Ministério Público, que toda sentença decorrente de um conflito de família é parte de um trágico drama. Deve ser criado um amplo espaço de atuação para os mediadores e conciliadores. Por outro lado, nenhum outro campo do Direito exige mais do jurista, do legislador, do juiz, do Ministério Público e do advogado uma mentalidade aberta e um perfil próprio, suscetíveis para absorver prontamente as modificações e pulsações sociais que os rodeiam. [...] Exige-se do operador do Direito que seja pleno conhecedor da sociedade e do meio em que vive [...]. As questões de família abrem palco para o advogado e o juiz conciliador e mediador (VENOSA, 2013, p. 13).

A principal justificativa para este estudo é que mesmo diante do esforço legislativo na adequação e modernização do sistema jurídico, o direito de família carece de normas e mecanismos que facilitem o acesso à justiça e na implementação e concretização de direitos. Assim, propõe o trabalho tratar algumas das abordagens do novo CPC em relação ao direito de família e sucessões e o instituto da mediação.

\footnotetext{
${ }^{2}$ Vale lembrar Bittar (2005), quando afirma: [...] entre as ciências humanas ou sociais, a ciência jurídica é ciência normativa e aplicada. Comunga com as demais ciências sociais a natureza de um saber voltado para as preocupações não naturalísticas, mas valorativas. Aqui, o que está em jogo é o comportamento humano. O cerne do problema jurídico é o problema do valor [...] (BITTAR, 2005, p. 45).

${ }^{3}$ A expressão ética no campo da sociedade civil vai desde as organizações sem fins lucrativos, sindicatos, associações de bairros, como forças que se institucionalizam transmitindo valores sociais e participando das transformações do seu bairro, comunidade e alcança o mundo jurídico seja pela mediação, conciliação, arbitragem, ou mesmo na interpretação calcada em valores e princípios constitucionais tendo como fundamento a dignidade da pessoa humana [...] (OLIVEIRA SOBRINHO, 2015, p. 202).
} 
Concluímos destacando as inovações do CPC/2015 como relevantes para o fortalecimento de novas instituições no Estado Democrático de Direito com vista à participação democrática e deliberativa do cidadão por meio do incentivo à autocomposição. Nesse diapasão a mediação têm papel relevante, posto que visa incrementar uma cultura do diálogo (com vistas à satisfação de interesses) com perspectivas de mudanças paradigmáticas no direito de família e sucessões e seus reflexos no contexto jurídico-social.

\section{DESENVOLVIMENTO}

A elaboração e reformas dos códigos legais são tarefas dos legisladores, juristas e a sociedade partícipe desse processo e a vivenciar a realidade dos fatos e a pressionar por mudanças estruturais. $\mathrm{O}$ processo emancipatório social não se circunscreve à visão cartesiana ou simplificada dos fatos ou vivências humanas; é o campo das interações humanas e possibilidades pontuadas por variáveis, ora com avanços e retrocessos. A visão reducionista de que a prestação jurisdicional finda na sentença está superada, pois a jurisdição com foco somente no processo tem sido um descompasso atualmente frente aos novos desafios, e em especial, os familiares que se apresentam (BARBOSA, 2007).

Confundimos boa parte das atribuiçõos inerentes às instituições judiciárias e as respectivas competências de seus atores.

Para maior parte da população a figura do juiz resume todo o sistema de justiça. O judiciário é percebido não apenas como o poder que profere sentenças, julgando, mas, também, como uma instituição responsável por fornecer respostas às mais variadas demandas por justiça. Atribui-se ao juiz amplas funções: iniciar uma questão, identificar o culpado, prendê-lo, punilo e reparar o mal. E, mais ainda, sua sentença deveria obedecer aos cânones de uma justiça rápida, independente das provas, sensível à opinião pública. Enfim, espera-se do judiciário, justiça no sentido mais amplo do termo, como se coubesse ao juiz pronunciar-se tanto sobre questões que constam dos autos como sobre toda e qualquer iniquidade social [...]. (SADEK, 2010, p.11-12).

A consolidação da cultura e a prática da conciliação e mediação, por exemplo, exigirão por parte dos atores de uma renovada busca pela eficiência, sem que possamos perder o sentido da segurança jurídica em nome da celeridade. Destarte, o caráter de contingência, flexibilidade e sofisticação técnica do direito tende a encarecer cada vez mais o trabalho jurídico. O que por sua vez faz com que a maioria das pessoas, que não dispõe de posses o suficiente, acaba sendo marginalizada, e não tendo efetivados os seus direitos constitucionalmente assegurados. 
Diante desse quadro, dois instrumentos se revalorizam - a mediação ${ }^{4}$ e conciliação com vista à solução consensual na temática dos direitos disponíveis ou não disponíveis, com foco na mediação como um importante instrumento para a resolução de litígios no âmbito do Direito de Família.

\subsection{Direito de Família e Sucessões numa sociedade pontuada por ambivalências e pela busca por direitos.}

Muitas das fontes que interagem nas transformações sociais são reconhecidas como verdadeiras fontes de Direito, agora num sentido amplo, como observa Kelsen, para quem o termo fontes de direito possui diversas conotações. A principal delas é derivada do "fundamento de validade jurídico-positivo" relacionada com a norma jurídica e, mais especificamente, com a norma positivada hierarquicamente superior que é a Constituição (KELSEN, 2003).

Nesse sentido, a Constituição é a fonte das normas gerais produzidas por via
legislativa ou consuetudinária; e uma norma geral é a fonte da decisão
judicial que a aplica e que é representada por uma norma individual. Mas a
decisão judicial também pode ser considerada como fonte dos deveres ou
direitos das partes litigantes por ela estatuídos, ou da atribuição de
competência ao órgão que tem de executar esta decisão. Num sentido
jurídico-positivo, fonte do Direito só pode ser o Direito. Mas a expressão é
também empregada num sentido não jurídico quando com ela designamos
todas as representações que, de fato, influenciam a função criadora e a
função aplicadora do Direito, tais como, especialmente, os princípios morais
e políticos, as teorias jurídicas, pareceres de especialistas e outros (KELSEN,
2003, p. 259).

A instituição família evoluiu significativamente nas últimas décadas para além do modelo tradicional formada pelo casamento, ampliando seu conceito haja vista os novos costumes e valores.

Compreendida como um fenômeno social, a família sofre alterações compatíveis ao período em que está inserida, bem como modificações que visem acompanhar as condições econômicas, políticas e, principalmente, sociais de uma determinada coletividade [...]. Assim, a família é uma construção social, uma sociedade menor e, por assim se caracterizar, constitui o verdadeiro elemento sociológico (XAVIER, 2016, p. 39).

\footnotetext{
${ }^{4}$ A lei 13.140/2015 dispõe sobre a mediação entre particulares como meio de solução de controvérsias e sobre a autocomposição de conflitos no âmbito da administração pública. No $\S$ único do artigo $1^{\circ}$ estabelece que mediação é a atividade técnica exercida por terceiro imparcial sem poder decisório, que, escolhido ou aceito pelas partes, as auxilia e estimula a identificar ou desenvolver soluções consensuais para a controvérsia. Em seu
} 
art. $3^{\circ}$ estabelece que conflitos sobre os direitos disponíveis ou indisponíveis podem ser objeto de mediação desde que admitam transação. Em seu $\S 2^{\circ}$ esclarece que o consenso das partes envolvendo direitos indisponíveis, mas transigíveis, deve ser homologado em juízo, exigida a oitiva do Ministério Público (BRASIL, 2015).

As mudanças sociais vêm ganhando novos contornos; novos costumes e ideologias se apresentam em prol da plena concretização dos direitos fundamentais, o que favorece a ampliação do sistema, a mudança dos paradigmas e estruturas vigente, dos atores sociais nas reformulações normativas e implementação de direitos.

A título de exemplo cabe citar que o Supremo Tribunal Federal pacificou a temática do princípio da igualdade em relações homoafetivas e à entidade familiar. Essa foi uma decisão paradigmática ao estabelecer um parâmetro a essa nova realidade.

[...] Dessa forma, em relação à união homoafetiva e entidade familiar, destacou o Ministro Ayres Brito, que nada "obsta que a união de pessoas do mesmo sexo possa ser reconhecida como entidade familiar apta a merecer proteção estatal", concluindo que deve seguir 'as mesmas regras e com idênticas consequências da união estável heteroafetiva', aplicando interpretação conforme o art. 1723 do Código Civil [...] (MORAES, 2014, p. 40-41).

O direito das sucessões, por sua vez, em sua origem não possuía uma vinculação direta à transmissão patrimonial, mas uma transmissão de qualidade, de status de posição social na qualidade de chefe da família. O Direito Romano primitivo não possibilitava uma integração entre o testamento e o que se denominava de sucessão legítima, em que imperava a regra "nemo pro parte testatus pro parte intestatus decedere potest" (ninguém pode testar uma parte e outra não - tradução livre) (BARROS E DEROMA JÚNIOR, 2012, p. 191, grifo do autor).

Levando em conta suas particularíssimas características, talvez seja melhor considerar, no futuro bem próximo, o direito de família como um microssistema jurídico, integrante do denominado direito social, embora essa denominação seja redundante, na zona intermediária entre o direito público e o privado, possibilitando a elaboração de um Código ou Estatuto da Família [...] que albergasse todos os seus princípios, bem como regulasse também o direito sucessório, intimamente ligado à família, e o direito do menor e institutos correlatos. Não foi a posição do Código de 2002 que manteve o compartimento dedicado a esse campo jurídico (VENOSA, 2013, p. 11).

Os fenômenos sociais e econômicos, a entrada das mulheres no mercado de trabalho, a ampliação dos meios de dissolução do casamento e o planejamento familiar são algumas das inovações que contribuíram ao aumento das novas demandas sociais.

A concepção assistida com a gênese e o nascimento de filhos, por exemplo, inclusive de pais já falecidos (pelas técnicas de fecundação in vitro e conservação de embriões 
congelados) são procedimentos que impactam nas esferas da bioética e da justiça, com vista à realização de direitos, liberdade, igualdade e segurança.

A concepção de cidadania é fruto das conquistas das dimensões do Direito. E na percepção da práxis social e cultural essa ruptura Estado-Nação para Estado-cidadão precisa ser feita, assegurando que o próprio Estado cumpra a Constituição baseado em princípios, valores, construídos pela força democrática deliberativa participativa [...]. Será preciso trazer o povo a participar das decisões do próprio Estado mediante inclusão dos instrumentos de democracia acessíveis a todos [...] (OLIVEIRA SOBRINHO, 2015, p. 173).

A família que se constituía como expressão ao culto religioso doméstico ou das que se formaram como consequência da dominação patriarcal, do clã ou dos ritos tribais cederam espaço a novos arranjos classificados como pós-modernos e não se fundam apenas em relações de poder ou tradição, mas expressam sentimentos da realidade visando atender às aspirações pessoais e de felicidades de seus entes (MALUF, 2010).

[...] a regulação dos efeitos de um novo modo de pensar recai sobre o Direito, que é desconstruído, fragmentado, triturado, porque há um rompimento com as chamadas verdades absolutas, típicas do modernismo, sustentadas pelo racionalismo exacerbado. Eis a complexidade transformadora do comportamento, do modo de ver e de interpretar as leis, abrindo-se a mente racional para um movimento plural, de possibilidades [...] (BARBOSA, 2007, p. 30).

A união estável, a monoparentalidade, as uniões homoafetivas são famílias concebidos dentro e a partir do respeito às diferenças humanas, mas com respeito ao princípio da igualdade. Nesse diapasão, no julgamento dos Recursos Extraordinários 646721 e 878694, o STF equiparou a União Homoafetiva ao casamento para fins sucessórios ${ }^{5}$. (STF, 2017)

Experimenta-se uma crise nos grandes sistemas de valor - estado, religião e família, um niilismo, que tem como principal consequência a busca, muitas vezes desmedida, da felicidade individual ao alto preço da exclusão do outro. (MORIN, 2007)

O progresso é fruto das transformações dos variados dissensos e conflitos que permeiam a humanidade, cuja busca pela superação humana é um dos grandes achados concebido há séculos, o que também não é unanimidade de consenso.

[...] a liberdade e a segurança, ambas igualmente urgentes e indispensáveis, são difíceis de conciliar sem atrito - e atrito considerável na maior parte do

\footnotetext{
5 “O Supremo Tribunal Federal (STF) concluiu julgamento que discute a equiparação entre cônjuge e companheiro para fins de sucessão, inclusive em uniões homoafetivas. A decisão foi proferida no julgamento dos Recursos Extraordinários (REs) 646721 e 878694, ambos com repercussão geral reconhecida. No
} 
julgamento...os ministros declararam inconstitucional o artigo 1.790 do Código Civil, que estabelece diferenças entre a participação do companheiro e do cônjuge na sucessão dos bens.

O RE 878694 trata de união de casal heteroafetivo e o RE 646721 aborda sucessão em uma relação homoafetiva. A conclusão do Tribunal foi de que não existe elemento de discriminação que justifique o tratamento diferenciado entre cônjuge e companheiro estabelecido pelo Código Civil, estendendo esses efeitos independentemente de orientação sexual”. (STF, 2017)

tempo. Estas duas qualidades são, ao mesmo tempo, complementares e incompatíveis; a chance de que entrem em conflito sempre foi e sempre será tão grande quanto a necessidade de sua conciliação [...] A promoção da segurança sempre requer o sacrifício da liberdade, enquanto esta só pode ser ampliada à custa da segurança. Mas segurança sem liberdade equivale à escravidão [...] (BAUMAN, 2003, p. 24).

As novas mudanças nos padrões, valores e costumes culturais refletem no papel de distribuição da justiça. As questões ético-morais adaptam-se a novos conceitos, em que a liberdade, igualdade e segurança se mantêm como princípios básicos.

Não existe certeza absoluta, mas existe segurança suficiente para os propósitos da vida humana. Podemos e devemos presumir a verdade da nossa opinião, para orientarmos a nossa conduta. Cabe a mesma presunção quando proibimos os maus de perverter a sociedade pela propagação de opiniões que encaramos como falsas e perniciosas. [...] (MILL, 2006, p. 4748).

No caso brasileiro, buscou-se valorizar no novo $\mathrm{CPC}^{6}$, mais uma vez, as formas extrajudiciais de resolução de conflitos a serem realizados em centros judiciários ${ }^{7}$ cujo

\footnotetext{
${ }^{6}$ Esclarece Bueno (2015) que, "além da valorização das formas extrajudiciais, o novo CPC, quanto ao aspecto estrutural, inova em relação ao CPC anterior - e semelhantemente ao Código de Processo Civil de 1939 -, o novo CPC contém uma 'Parte Geral' em contraposição a uma 'Parte Especial'. Ele traz também um 'Livro Complementar'. Na Parte Geral são disciplinados, dentre outros, os princípios e as garantias fundamentais do processo civil (arts. $1^{\circ}$. a $11^{\circ}$.); estabelecida ordem cronológica de conclusão para proferir sentenças ou acórdãos (art. 12); a aplicação das normas processuais (arts. 13 a 15); os contornos da 'jurisdição e da ação', cabendo destacar que a 'impossibilidade jurídica do pedido' deixou de ser uma das condições da ação e que, embora interesse e legitimidade lá estejam, não figuram no novo CPC como condiçães (art.17); os limites da jurisdição nacional e, inovando, uma interessante disciplina a respeito da cooperação internacional, inclusive por 'auxílio direto' (art. 21 a 41); a competência (arts. 42 a 66); a cooperação nacional (arts. 67 a 69); os sujeitos do processo, incluindo uma bem modificada e mais completa disciplina sobre os honorários advocatícios, cabíveis, inclusive em grau recursal (arts. 70 a 97); gratuidade da justiça (arts. 98 a 102); as funções essenciais à administração da Justiça, distinguindo, com nitidez, o juiz (e seus auxiliares), do Ministério Público, da advocacia pública e da defensoria pública (arts. 139 a 187); atos processuais (arts. 188 a 293), com a importante novidade de que os prazos processuais só correrão em dias úteis (art. 219, caput) e as normas relativas à formação, à suspensão e à extinção do processo (arts. 312 a 317)”. (BUENO, 2015, p. 17-18).

${ }^{7}$ Conforme Câmara (2015), vale ressaltar que: "A composição e organização destes centros deve ser feita pelos tribunais, respeitadas as disposições estabelecidas pelo Conselho Nacional de Justiça (art. 165, § $1^{\circ}$; art. 24, parágrafo único, da Lei n. 13.140/2015). Nesses centros, porém, será respeitada a distinção entre conciliação e mediação. A conciliação é o mecanismo de solução consensual indicado para conflitos surgidos em casos nos quais não haja vínculos intersubjetivos entre os litigantes (como se dá, por exemplo, na relação entre comprador de um produto e a loja em que o mesmo tenha sido adquirido). Neste caso, atua o conciliador, a quem incumbe propor soluções possíveis para o litígio, sendo vedada a utilização de qualquer constrangimento ou intimidação (art. $165, \S 2^{\circ}$.). De outro lado, é adequada a utilização da mediação em casos nos quais exista vínculo intersubjetivo entre os litigantes, como se dá em conflitos de família ou em litígios societários. Nesses casos,
} 
atuará o mediador, a quem incumbe auxiliar os interessados a compreender as questões e os interesses em conflito, de modo que possam eles restabelecer suas comunicações e identificar, por si próprios, soluções consensuais (art. 165, $\S 3^{\circ}$.). É que, conforme definição legal, mediação é "a atividade técnica exercida pelo terceiro imparcial sem poder decisório, que, escolhido ou aceito pelas partes, as auxilia e estimula a identificar ou desenvolver soluções consensuais para a controvérsia" (art. 1º., parágrafo único, da Lei n. 13.140/2015). Perceba-se, então, uma diferença fundamental entre a atuação do conciliador e a do mediador. É que aquele deve propor soluções possíveis para o conflito, enquanto a este não é dado fazê-lo, cabendo-lhe tão somente auxiliar as partes a identificar, por si próprias, as possíveis soluções consensuais para o litígio [...]” (CÂMARA, 2015, p. 118).

principal objetivo seja o estímulo à autocomposição (artigos 24 e 165 do novo CPC), a ser tratado no tópico seguinte.

\subsection{Princípios e inovações nas questões relacionadas ao direito de família no novo CPC.}

O processo civil brasileiro encontra fundamento na Constituição ao que se denomina de "modelo constitucional de processo civil", ou seja:

É uma expressão que designa o conjunto de princípios constitucionais destinados a disciplinar o processo civil (e não só o civil, mas todo e qualquer tipo de processo) que se desenvolve no Brasil. Começando pelo princípio que a Constituição da República chama de devido processo legal (mas que deveria ser chamado de devido processo constitucional) [...] (CÂMARA, 2015, p. 5, grifo do autor).

Ao tentar reunir em dois grupos os princípios essenciais para o direito de família, ressalte-se que o primeiro seja formado pelos princípios gerais do Direito (dignidade da pessoa humana, igualdade, vedação ao retrocesso) e, o segundo, pelos princípios especiais afetos ao direito de família (afetividade, solidariedade familiar, função social da família, proteção à criança e ao adolescente, convivência familiar e proteção ao idoso). Observamos que a dignidade humana adquire relevância à medida em que se respeite a dimensão existencial do ser humano de per se e no conjunto de suas relações familiares e sociais. (GAGLIANO, 2012)

A ideia de dignidade relaciona-se intrinsecamente aos direitos fundamentais de natureza supralegal e que se classificam como direitos pétreos de aplicação direta porque vinculam, de imediato, quaisquer instituições. (FERMENTÃO, FIGUEIREDO E FIGUEIREDO, 2015).

Em relação à união estável trazida pelo novo $\mathrm{CPC}$ - mantendo certa similitude às regras do CPC/1973 após o advento da Lei 11.441/2007 - passou a prever a possibilidade de sua extinção consensual por escritura pública. Dessa forma, ampliam-se as possibilidades nos moldes traçados na Lei 11.441/2007 em relação ao divórcio e à separação consensual. 
(BRASIL, 2007)

O artigo 733, 'caput' do novo CPC preserva o mesmo sentido do artigo 1.124-A, 'caput' do CPC/1973. Todavia, o legislador inovou ao incluir na redação a possibilidade de se realizar também 'a extinção consensual da união estável' por meio de escritura pública. Além disso, o texto do dispositivo legal foi simplificado: substitui-se a frase 'relativas à descrição e à partilha dos bens comuns e à pensão alimentícia' e, ainda, 'ao acordo quanto à retomada pelo cônjuge de seu nome de solteiro ou à manutenção do nome adotado quando se deu o casamento' por, tão somente, 'de que trata o art. 731'. Embora o legislador tenha efetuado estas modificações

redacionais, o divórcio consensual, a separação consensual e a extinção consensual da união estável, não havendo nascituro ou filhos incapazes e observados os requisitos legais, continuam podendo ser realizados por escritura pública, da qual constarão as disposições de que trata o artigo 731 deste Diploma Legal (IMHOF, 2015, p. 685).

Outra questão trazida é a relacionada à reprodução humana assistida com a possibilidade de se gerar filhos após o falecimento de um ou ambos os genitores, cuja inovação impactará no direito sucessório (VENOSA, 2011, p. 50).

O direito de família possui relação importante com os demais ramos da ciência jurídica. $\mathrm{O}$ direito de família influi diretamente no direito sucessório, cujo objetivo é especialmente, diante da morte do de cujus, a perpetuidade dos bens no patrimônio familiar. O direito das coisas também se encontra relacionado com o direito de família, conferindo-se, por lei, direitos reais sobre determinados bens em favor de um ou alguns membros da família. $\mathrm{O}$ direito das obrigações inspira a fixação dos deveres dos membros da família, observada a natureza diversa da chamada obrigação familiar [...] (LISBOA, 2012, p. 35-36).

Conforme Hironaka e Pereira (2007), a sucessão ${ }^{8}$ processual e a suspensão automática do processo com a morte - artigo 110 do novo CPC com redação semelhante ao artigo 43 do CPC/1973 - são eventos de importância e que, necessariamente, influenciam o Direito das Sucessões.

O Direito das Sucessões opera por meio da morte do titular de um direito que não seja personalíssimo e que, nesta medida, possa e deva ser transferido para um outro titular. Assim, sempre que um direito ou bem qualquer puder ser transferido para outra pessoa em razão da morte de seu antigo titular, estar-se-á diante do campo propício para a aplicação das regras do direito sucessório. Daí dizer-se tratar de sucessão mortis causa [...] (HIRONAKA E PEREIRA, 2007, p. 15-16)

Casos há em que o falecido não declarou sua última vontade em testamento -morte $a b$ intestato -, o que implica a abertura da sucessão para realizar o endereçamento de bens, direitos e obrigações conforme os artigos 1.829 e 1.845 do Código Civil, sem prejuízo da 


\begin{abstract}
${ }^{8}$ Conforme Imhof (2015): “[...] a) a sucessão processual compreende, exclusivamente, a substituição das partes no processo, enquanto na substituição processual propriamente dita, não há lugar para se falar em modificação dos sujeitos ativos e passivos da relação jurídica processual por se estar em juízo em nome próprio e apenas na defesa do direito de outrem; b) a sucessão processual ocorre quando o processo está em curso, enquanto a substituição processual se cristaliza, desde logo, na inauguração da relação processual; c) a causa da sucessão processual é a ocorrência de qualquer modificação subjetiva na relação jurídica de direito material, por ato voluntário 'inter vivos' ou por 'causa mortis', com reflexos diretos na continuidade da presença dos sujeitos processuais que iniciaram a relação jurídica formal; na substituição processual não há a ocorrência deste fenômeno; d) com a sucessão processual ocorre, imediatamente, a substituição do titular originário da relação jurídica formal pelo novo sujeito que assume o feito na situação em que o mesmo se encontrar, turbulência esta irrealizável na pura substituição processual”. (IMHOF, 2015, p. 108).
\end{abstract}

adoção, conforme o caso, da "regra especial, ex vi do disposto no art. 1.790, do mesmo

Diploma Legal” (HIRONAKA E PEREIRA, 2007, p. 16).

Quadro 1 - Sucessão ao invés de substituição pelo evento morte

\begin{tabular}{|c|c|}
\hline Artigo/Redação no novo CPC & Artigo/Redação no CPC/1973 \\
\hline $\begin{array}{l}\text { Art. 110. Ocorrendo a morte de qualquer das } \\
\text { partes, dar-se-á a sucessão pelo seu espólio ou } \\
\text { pelos seus sucessores, observado o disposto no } \\
\text { art. } 313, \S \S 1^{\circ} \text {. e } 2^{\circ} \text {. }\end{array}$ & $\begin{array}{l}\text { Art. } 43 \text {. Ocorrendo a morte de qualquer das partes, dar-se- } \\
\text { á a substituição pelo seu espólio ou pelos seus sucessores, } \\
\text { observado o disposto no art. } 265 \text {. }\end{array}$ \\
\hline \multicolumn{2}{|c|}{$\begin{array}{l}\text { Nota: “O artigo } 110 \text { do novo CPC reproduz o mesmo sentido do artigo } 43 \text { do CPC/1973, tendo o legislador } \\
\text { substituído o vocábulo 'substituição' por 'sucessão', corrigindo, assim, uma imperfeição conceitual. Deste } \\
\text { modo, ocorrendo a morte de qualquer das partes no curso do processo, dar-se-á a sucessão pelo seu espólio ou } \\
\text { pelos seus sucessores, observado o disposto no artigo } 313 \text {, parágrafos primeiro e segundo do novo CPC. O } \\
\text { artigo 313, inciso I do novo CPC trata da suspensão do processo pelo evento morte [...]” (IMHOF, 2015, p. } \\
\text { 109) }\end{array}$} \\
\hline
\end{tabular}

Fonte - Imhof (2015).

O Enunciado no 187 do Fórum Permanente de Processualistas Civis chama atenção ao prescrever que: "No emprego de esforços para a solução consensual do litígio familiar, são vedadas iniciativas de constrangimento ou intimidação para que as partes conciliem, assim como as de aconselhamento sobre o objeto da causa" (BUENO, 2015, p. 151).

As inovações trazidas pelo novo CPC demonstram o desafio a ser enfrentado até que se supere a cultura da judicialização dos conflitos à medida que as possibilidades se ampliam à concretização dos direitos.

Quadro 2 - Conciliação e Mediação Art. 166 
Art. 166. A conciliação e a mediação são informadas pelos princípios da independência, da imparcialidade, da autonomia da vontade, da confidencialidade, da oralidade, da informalidade e da decisão informada.

$\S \mathbf{1}^{\mathbf{0}} \ldots$

$\S 2^{\circ} \ldots$

Sem correspondência

$\$ 3^{\circ} \ldots$

\$4 $\mathbf{4}^{\mathbf{0}}$. A mediação e a conciliação serão regidas conforme a livre autonomia dos interessados, inclusive no que diz respeito à definição das regras procedimentais.

Nota: "Correspondência no Anteprojeto: art. 134. O art. 166 se ocupa com os princípios regentes da conciliação e da mediação: independência, imparcialidade, autonomia da vontade, confidencialidade, oralidade, informalidade e decisão informada. Havia um oitavo princípio, da normalização do conflito, que acabou sendo retirado na última etapa do processo legislativo perante o Senado Federal. Os parágrafos trazem importantes elementos em relação ao alcance e à configuração da confidencialidade ( $\S 1^{\circ}$. e $2^{\circ}$.), da imparcialidade $\left(\S 3^{\circ}\right.$.) e da autonomia da vontade $\left(\S 4^{\circ}\right)$ '”. (BUENO, 2015, p. 151)

Fonte - Bueno (2015).

No Quadro 3 citam-se os dispositivos constantes no artigo 167 que trata em linhas gerais da organização do cadastro nacional e dos cadastros relativos ao registro dos conciliadores, mediadores e das câmaras privadas no Tribunais de Justiça e TRF, tudo com vistas à um controle sobre a qualidade do serviço prestado obedecidos os princípios éticos a serem seguidos nos termos da legislação vigente, em especial na lei 13.140 e resolução 125 do CNJ. Dessa forma, o direito de família sofreu alterações significativas, em que o legislador se preocupou em fazer uma revalorização do instituto da mediação. A Lei $n^{\circ}$ 13.140/2015, em seu artigo $2^{\circ}$, elenca os princípios básicos a serem observados ao se estabelecer a técnica da mediação: I - imparcialidade do mediador; II - isonomia entre as partes; III - oralidade; IV - informalidade; V - autonomia da vontade das partes; VI - busca do consenso; VII - confidencialidade; VIII - boa-fé. (BRASIL, 2015)

Quadro 3 - Conciliação e Mediação Art. 167

\begin{tabular}{|c|c|}
\hline Artigo/Redação no novo CPC & Artigo/Redação no CPC/1973 \\
\hline 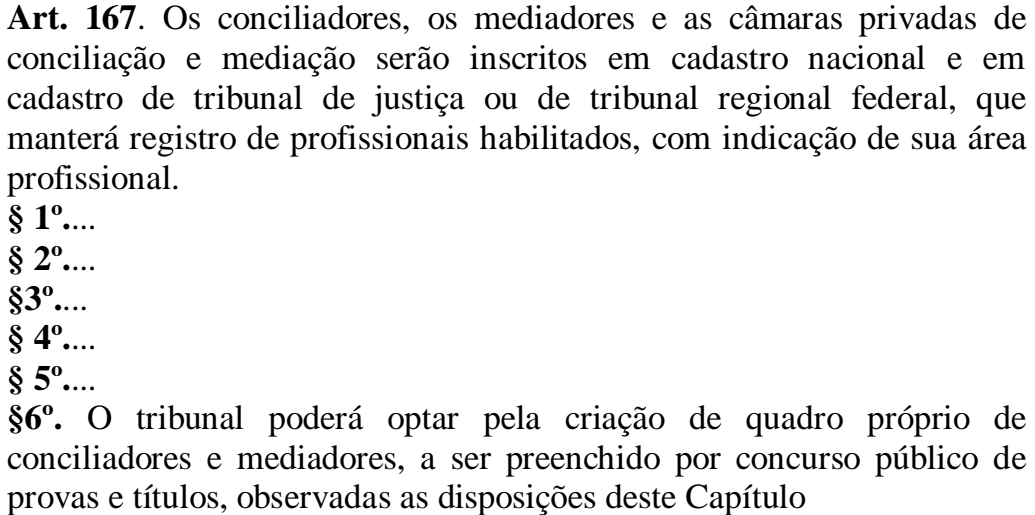 & Sem correspondência \\
\hline
\end{tabular}


Nota: "Correspondência no Anteprojeto: art. 137. O art. 167, no caput e seus $\S \S 1^{\circ}$. a $4^{\circ}$. trata dos cadastros de conciliadores e mediadores a serem formados e sempre mantidos atualizados pelos tribunais, estabelecendo as condições mínimas para viabilizar a inscrição. Cabe o destaque, a propósito, do $\S 6^{\circ}$. sobre a possibilidade de o tribunal, mediante concurso público, criar quadro próprio de conciliadores e mediadores " (BUENO, 2015, p. 151-152)

Fonte - Bueno (2015).

Os Quadros 4 a 7 remetem aos artigos 693 a 699 do Capítulo X - Das Ações de Família, que significaram importantes inovações. (IMHOF, 2015)

A legislação prioriza uma autêntica política de Estado na busca pela solução consensual de resolução de conflitos. Especialmente pela primazia da mediação como instrumento utilizado na conjugação de esforços na busca da satisfação de interesses das partes, assegurados a proteção dos direitos indisponíveis de crianças e adolescentes. Restanos vislumbrar uma prática jurisdicional que permita a formação de uma cultura do diálogo com vistas à pacificação social.

Quadro 4 - Capitulo X Das Ações de Família - Art. 693

\begin{tabular}{|l|c|}
\hline \multicolumn{1}{|c|}{ Artigo/Redação no novo CPC } & Artigo/Redação no CPC/1973 \\
\hline $\begin{array}{l}\text { Art. 693. As normas deste Capítulo aplicam-se aos processos } \\
\text { contenciosos de divórcio, separação, reconhecimento e extinção da } \\
\text { união estável, guarda, visitação e filiação. } \\
\text { Parágrafo único. .... }\end{array}$ & Sem correspondência \\
\hline $\begin{array}{l}\text { Nota: "Os artigos 693 ao 699 do novo CPC tratam das ações de família, uma inovação significativa. Este } \\
\text { Capítulo se aplica aos processos contenciosos de divórcio, separação, reconhecimento e extinção de união } \\
\text { estável, guarda, visitação e filiação. Já a ação de alimentos e a que versar sobre interesse da criança ou de } \\
\text { adolescente, segundo expressamente determina o parágrafo único, deverá observar o procedimento previsto em } \\
\text { legislação específica, aplicando-se, no que couber, as disposições deste Capítulo [...] quis o legislador, nas } \\
\text { 'ações de família' (processos contenciosos de divórcio, separação, reconhecimento e extinção de união estável, } \\
\text { guarda, visitação e filiação), que todos os esforços sejam empreendidos para a solução consensual das } \\
\text { controvérsias nelas surgidas" (IMHOF, 2015, p. 649). }\end{array}$ \\
\hline
\end{tabular}

Fonte - Imhof (2015).

Situações corriqueiras como essas em que a atuação dos juízes pode ser substituída pela autocomposição. Parafraseando Sófocles na tragédia Antígona, no centro nervoso das decisões jurídicas há quase sempre uma situação que coloca o intérprete da lei diante da escolha entre dois bens. A ação decisória - a sentença - leva a um fenômeno que exclui um deles em detrimento do outro. O juiz ao escolher um, já pressente de alguma forma as sombras da perda que invariavelmente ocorrerá; e que precisa ser entendida não como uma decisão tendenciosa, mas uma limitação inerente à decisão humana incapaz de realizar todos os bens em um único ato (ROSENFIELD, 2002).

Diversamente, os meios extrajudiciais entre os quais a conciliação e a mediação se 
adequam a uma realidade do mundo globalizado em que as decisões são dialogadas, compartilhadas, e exigem um esforço de todos para se debruçar não sobre o conflito, mas nas questões implícitas relacionadas ao convívio social, e ao próprio individualismo.

É que as soluções consensuais são, muitas vezes, mais adequadas do que a imposição jurisdicional de uma decisão, ainda que esta seja construída democraticamente através de um procedimento em contraditório, com efetiva participação dos interessados. E é fundamental que se busquem soluções adequadas, constitucionalmente legítimas, para os conflitos, soluções estas que muitas vezes deverão ser consensuais [...]. (CÂMARA, 2015, p. 5-6).

Infere-se, portanto, que em determinados contenciosos nos quais os mecanismos extrajudiciais podem diluir tal incapacidade-limitação dos operadores da lei, far-se-á uma diluição, ou mesmo, uma contenção dos reflexos ou ressentimentos da "sombra da perda" nas decisões a serem tomadas. O pensamento girardiano lança um olhar sobre tais sombras; a perda, em algumas situações, pode ser uma oportunidade de aprendizado e evolução (GIRARD, ANTONELLO E ROCHA (2011)

O mundo moderno é ultra individualista, quer que o desejo seja estritamente individualizado, único. Em outras palavras, meu apego ao objeto do desejo é de certo modo predeterminado. Se o desejo é só meu, eu sempre desejo as mesmas coisas. E se o desejo é fixo, não há mais diferença entre instinto e desejo [...]. É graças à mobilidade do desejo, à sua natureza mimética e à instabilidade de nossas identidades que temos a capacidade de adaptar-nos, e a possibilidade de aprender e de evoluir. (GIRARD, ANTONELLO E ROCHA, 2011, p. 81).

A mudança cultural é um lento processo e mesmo que existam códigos legais que apoiem e sistematizem tais fenômenos, revela-se como uma tarefa de gerações e pautada como meta factível.

Quadro 5 - Capitulo X Das Ações de Família - Art. 694

\begin{tabular}{|l|r|}
\hline \multicolumn{1}{|c|}{ Artigo/Redação no novo CPC } & Artigo/Redação no CPC/1973 \\
\hline Art. 694. Nas ações de família, todos os esforços serão empreendidos & \\
para a solução consensual da controvérsia, devendo o juiz dispor do & \\
auxílio de profissionais de outras áreas de conhecimento para a & \\
mediação e conciliação. Parágrafo único. A requerimento das partes, & Sem correspondência \\
o juiz pode determinar a suspensão do processo enquanto os litigantes & \\
se submetem a mediação extrajudicial ou a atendimento & \\
multidisciplinar. & \\
\hline
\end{tabular}


Nota: "Este inovador artigo, de forma explícita, disciplina que todos os esforços serão empreendidos para a solução consensual da controvérsia envolvendo as ações de família. Portanto, o Juiz disporá do auxílio de profissionais de outras áreas de conhecimento para a mediação e conciliação, sendo lícito, inclusive, a requerimento das partes, a suspensão do processo enquanto as mesmas se submetem a mediação extrajudicial ou a atendimento multidisciplinar" (IMHOF, 2015, p. 650).

Fonte - Imhof (2015).

Com a suspensão do processo parece haver um estado de desequilíbrio ou a descontinuidade do regular processamento do feito, mas em verdade isso contribui para que a tarefa de mediadores e conciliadores seja a constante busca por mudanças comportamentais positivas que auxiliem as partes a tomarem consciência crítica e de reagirem de forma eficaz e positiva para resolução das suas várias situações conflituosas.

O artigo 695 do novo CPC disciplina a citação, após recebimento da petição inicial e, nas situações cabíveis, as providências atinentes à tutela provisória nas ações de família. O artigo 696 trata do número de sessões de audiências de mediação e conciliação e quantas forem necessárias para uma solução negociada. (IMHOF, 2015).

Quadro 6 - Capitulo X Das Ações de Família - Art. 695 e 696

\begin{tabular}{|c|c|}
\hline Artigo/Redação no novo CPC & Artigo/Redação no CPC/1973 \\
\hline $\begin{array}{l}\text { Art. 695. Recebida a petição inicial e, se for o caso, tomadas as } \\
\text { providências referentes à tutela provisória, o juiz ordenará a citação do réu } \\
\text { para comparecer à audiência de mediação e conciliação, observado o } \\
\text { disposto no art. } 694 \text {. } \\
\S \mathbf{1}^{\mathbf{0}} \ldots \\
\S \mathbf{2}^{\mathbf{o}} \ldots \\
\$ \mathbf{3}^{\mathbf{0}} \ldots \\
\S \mathbf{4}^{\mathbf{0}} \ldots\end{array}$ & Sem correspondência \\
\hline $\begin{array}{l}\text { Art. 696. A audiência de mediação e conciliação poderá dividir-se em } \\
\text { tantas sessões sejam necessárias para viabilizar a solução consensual, sem } \\
\text { prejuízo de providências jurisdicionais para evitar o perecimento do } \\
\text { direito. }\end{array}$ & Sem correspondência \\
\hline \multicolumn{2}{|c|}{$\begin{array}{l}\text { Nota: Ambos artigos podem ser considerados como inovações significativas em relação ao CPC/1973, neste } \\
\text { artigo e em seus respectivos parágrafos estão descritos os procedimentos que deverão ser observados nas ações } \\
\text { de família, procedimentos relacionados aos passos logo a tomada de conhecimento pela petição inicial. As } \\
\text { audiências de mediação e conciliação não impedem as providências jurisdicionais no sentido de que se impeça, } \\
\text { caso necessário, o "perecimento do direito" (IMHOF, 2015, p. 651). }\end{array}$} \\
\hline
\end{tabular}
Fonte - Imhof (2015).

Quando esgotadas as possibilidades de acordo entre as partes, o artigo 697 prevê a incidência das regras do procedimento comum de acordo com o artigo 335 - que regulamenta os procedimentos do termo inicial para o oferecimento da contestação. (IMHOF, 2015, p. 651). Nesse diapasão vale destacar a distinção entre legitimação e legitimidade: a primeira implica uma relação direta com uma condição especial que é a de se poder celebrar atos ou negócios jurídicos, e a segunda é termo afeto ao direito processual 
civil e uma das condições da ação. (TARTUCE, 2015)

A legitimação é uma condição especial para celebrar um determinado ato ou negócio jurídico. A título de exemplo, determina o art. 1.647 da atual codificação que, para determinados atos (vender imóvel, fazer doação, prestar fiança e aval), se casado for o celebrante, é necessária a autorização do cônjuge, a outorga conjugal (uxória - da mulher; ou marital - do marido). Não havendo respeito a essa legitimação, o negócio é anulável, desde que proposta ação pelo cônjuge, no prazo decadencial de 2 (dois) anos, contados do fim da sociedade conjugal (art. 1.649 do CC) [...] (TARTUCE, 2015, p. 130-131).

Os artigos 698 e 699 contemplam as situações de intervenção do Ministério Público e as normas para tomada de depoimento do incapaz ${ }^{9}$ mediante acompanhamento de profissional habilitado.

\footnotetext{
${ }^{9}$ Quanto à capacidade civil, Tartuce (2015) faz um paralelo entre a capacidade de direito e de fato: "A capacidade civil, em sentido genérico, pode ser assim classificada: - Capacidade de direito ou de gozo: é aquela comum a toda pessoa humana, inerente à personalidade, e que só se perde com a morte prevista no texto legal, no sentido de que toda pessoa é capaz de direitos e deveres na ordem civil (art. $1^{\circ}$. Código Civil); - Capacidade de fato ou de exercício: é aquela relacionada com o exercício próprio dos atos da vida civil. Toda pessoa tem capacidade de direito, mas não necessariamente a capacidade de fato, pois pode lhe faltar a consciência sã para o
}

Quadro 7 - Capitulo X Das Ações de Família - Art. 697 a 699

\begin{tabular}{|l|c|}
\hline \multicolumn{1}{|c|}{ Artigo/Redação no novo CPC } & Artigo/Redação no CPC/1973 \\
\hline $\begin{array}{l}\text { Art. 697. Não realizado o acordo, passarão a incidir, a partir de então, as } \\
\text { normas do procedimento comum, observado o art. 335. }\end{array}$ & Sem correspondência \\
\hline $\begin{array}{l}\text { Art. 698. Nas ações de família, o Ministério Público somente intervirá } \\
\text { quando houver interesse de incapaz e deverá ser ouvido previamente à } \\
\text { homologação do acordo. }\end{array}$ & Sem correspondência \\
\hline $\begin{array}{l}\text { Art. 699. Quando o processo envolver discussão sobre fato relacionado a } \\
\text { abuso ou alienação parental, o juiz, ao tomar o depoimento do incapaz, } \\
\text { deverá estar acompanhado por especialista. }\end{array}$ & \\
\hline
\end{tabular}

Nota: Os três artigos apresentam inovações significativas em relação ao CPC/1973. Especificamente quanto à proteção dos interesses dos incapazes, nota-se, em relação ao previsto no art. 698 a previsão de intervenção do Ministério Público, bem como, o assessoramento de especialista na tomada de depoimento do incapaz, "quando o processo envolver a discussão sobre fato relacionado a abuso ou alienação parental" (IMHOF, 2015, p. 651).

Fonte - Imhof (2015).

As mudanças dos paradigmas nas relações do direito de família e sucessões e na efetividade de justiça vão depender da percepção da sociedade na compreensão do longo e desgastante processo judicial se comparado às novas oportunidades que se ampliam pela mediação e conciliação ${ }^{10}$ trazidas no novo CPC. Uma solução que seja alcançada com a participação de mediadores e pela autocomposição favorece a resolução de muitos dos conflitos familiares, o que contribui positivamente ao sistema e, principalmente pela solução, 
a partir do diálogo, das muitas situações conflituosas.

O legislador avançou significativamente ao valorizar os meios consensuais ${ }^{11} \mathrm{de}$ resolução dos litígios conforme se vê na redação dos artigos 167 a 175, estendendo, inclusive,

exercício dos atos de natureza privada. Desse modo, a capacidade de direito não pode, de maneira alguma ser negada a qualquer pessoa, podendo somente sofrer restrições quanto ao seu exercício". (TARTUCE, 2015, p. 130).

${ }^{10}$ Conforme expõe Rocha (2016): “[...] o Novo CPC demonstra que o Direito pode operar com a perspectiva de conhecimentos não estritamente jurídicos, sem que com isso perca a sua função sistêmica ou passe a atuar sob a forma de corrupção sistêmica (ou seja, com o código dos outros sistemas). Isso se evidencia quando há proposição de uma audiência que inclui conciliação e mediação. Por outro lado, percebe-se que certo fechamento operacional do Direito é preservado, posto que a atuação multidisciplinar propriamente dita é delegada para os operadores dos demais sistemas como a Psicologia, Serviço Social, Pedagogia, entre outros. Entretanto, trata-se de um auxílio, como o próprio Código menciona, não excluindo, portanto, que os conciliadores e mediadores sejam oriundos do sistema jurídico". (ROCHA et al, 2016, p. 130).

${ }^{11}$ Neste sentido Tartuce, Dellore e Marin (2014) esclarecem: "Conciliação - possibilidades: [...] Sob a perspectiva processual, vale destacar que a audiência preliminar só será de realização obrigatória se a causa versar sobre direitos que admitem transação. Caberá a dispensa de sua realização, segundo $\S 3^{\circ}$. do art. 331 , se sobre o direito não for admissível acordo, ou se as circunstâncias da causa evidenciarem ser improvável sua obtenção. Merecem análise tais fatores porque, ante sua ocorrência, o juiz poderá, desde logo, sanear o processo e ordenar a produção da prova [...] É tradicional associar a disponibilidade do direito ao seu caráter patrimonial (pecuniário); em sentido genérico, todos os direitos podem ser considerados suscetíveis de transação seja quanto às suas modalidades, seja quanto à sua validade ou à sua extensão; o que se requer é que se trate de um objeto física e juridicamente apto a constituir objeto de contrato, devendo ainda ser certo, determinado e preciso. Havendo, portanto, poder de disposição por parte do titular do direito, nada obsta a verificação da autocomposição nos campos de família, patrimonial, obrigacional ou de qualquer outro ramo [...]" (TARTUCE, DELLORE E MARIN, 2014, p. 172-173).

"os benefícios da mediação e da conciliação para a Administração Pública, e que poderá ser implementada pela edição de leis próprias de cada ente federado" (BUENO, 2015, p. 155). Em relação à mediação no direito de família, lembra Andrade (2006) que as partes devem expor seus interesses em conflito. Ou seja, estabelecer o grau de complexidade das situações conflituosas. ${ }^{12}$ (NOGUEIRA et al, 2009)

Para construir uma cultura de paz, ou cultura da paz, como preferem alguns, é preciso conhecer as gêneses da violência (física e emocional) bem como o conflito ${ }^{13}$. (PELIZZOLI, 2010)

Assim, faz-se mister, buscar as causas da lide: tanto interiores, como o que nasce do desacordo entre as nossas necessidades e as de nossos semelhantes. (ROSENBERG, 2006)

Marshall B. Rosenberg atuou como mediador em várias situações de conflitos, desde que querelas entre proprietários de terras na Carolina do Norte e trabalhadores rurais migrantes, até mesmo entre grupos de israelenses e palestinos. Essa rica experiência confirma a dificuldade das pessoas em pensar em termos de necessidades, ao invés de apontar o que 
está errado na conduta alheia. O sucesso de um processo de mediação está relacionado à capacidade de comunicação por parte do mediador e dos partícipes. Ou seja, quanto mais conseguirem expressar suas reais necessidades sem se preocupar com juízos apressados das atitudes um dos outros, maior a chance de obterem êxito. (ROSENBERG, 2006).

A felicidade das pessoas não pode ser encontrada pela violência, mas pela cultura da $\operatorname{paz}^{14}$ (ZEHR, 2008)

\footnotetext{
${ }^{12}$ Segundo Nogueira (2009): “A Mediação em divórcio e separação, e em outras questões relativas a conflitos familiares que das duas primeiras advêm, ocupa um espaço à parte, pois a situação de ruptura envolve aspectos legais e emocionais [...] se as partes não buscam o caminho de decisão, arriscam-se a ter de acatar soluções sobre seus questionamentos práticos e jurídicos, que ficam longe do desejável e do que seria uma decisão apreciada por ambas as partes [...]" (NOGUEIRA et al, 2009, p. 10).

${ }^{13}$ Um conflito pode ser definido como a diferença entre dois objetivos que são buscados por parte de uma sociedade, ou seja, o conflito existe quando duas ou mais pessoas entram em desacordo porque as suas opiniões, desejos, valores e/ou necessidades são incompatíveis. Consequentemente, frente ao conflito, as pessoas em geral assumem três tipos de atitudes: 1) ignoram os conflitos; 2) respondem de forma violenta aos conflitos; 3 ) lidam com os conflitos de forma não-violenta, por meio do diálogo/consenso. Com certeza as duas primeiras alternativas não são as melhores, mas quando se aprende a lidar com o conflito de forma não-violenta, de forma justa e pacífica, essa é a melhor das opções para restaurar a paz. Portanto, para construir e encarar os conflitos de forma não violenta é preciso mudar atitudes, crenças e comportamentos (PELIZZOLI, 2010).

${ }^{14}$ Sobre cultura da paz e justiça restaurativa destacamos que: "[...] é tirando o crime de seu pedestal abstrato. Isto significa compreendê-lo como a Bíblia compreendia e da forma como nós o vivenciamos: como um dano e uma violação de pessoas e relacionamentos. A justiça deveria se concentrar na reparação, em acertar o que não está certo. Nesse caso, duas lentes bem diferentes poderiam ser descritas da seguinte forma: Justiça retributiva - O crime é uma violação contra o Estado, definida pela desobediência à lei e pela culpa. A justiça determina a culpa e inflige dor no contexto de uma disputa entre ofensor e Estado, regida por regras sistemáticas. Justiça restaurativa - $\mathrm{O}$ crime é uma violação de pessoas e relacionamentos. Ele cria a obrigação de corrigir erros. A justiça envolve a vítima, o ofensor e a comunidade na busca de soluções que promovam reparação, reconciliação e segurança" (ZEHR, 2008. p. 170-171).
}

A mediação familiar é relevante instrumento à paz social, na medida em que as partes olhem para os seus sentimentos, emoções e não para o conflito em si.

Muitas coisas em um conflito estão ocultas, mas podemos senti-las. Se tentarmos entendê-las, não encontraremos nada, corremos o risco de agravar o problema. Para mediar, como para viver, é preciso sentir o sentimento. $\mathrm{O}$ mediador não pode se preocupar por intervir no conflito, transformá-lo. Ele tem que intervir sobre os sentimentos das pessoas, ajudá-las a sentir seus sentimentos, renunciando a interpretação. Os conflitos nunca desaparecem, se transformam; isso porque, geralmente, tentamos intervir sobre o conflito e não sobre o sentimento das pessoas. Por isso, é recomendável, na presença de um conflito pessoal, intervir sobre si mesmo, transformar-se internamente, então, o conflito se dissolverá (se todas as partes comprometidas fizerem a mesma coisa) [...]. Quando as pessoas interpretam (interpretar é redefinir), escondem-se ou tentam dominar (ou ambas as coisas). Quando as pessoas sentem sem interpretar, crescem.

[...] A energia que está sendo dirigida ao ciúme, à raiva, à dor tem que se tornar silêncio. A pessoa, quando fica silenciosa, serena, atinge a paz interior, a não violência, a amorosidade. Estamos a caminho de tornarmo-nos liberdade. Essa é a meta mediação. (WARAT, 2004, p. 26) 
Vislumbramos a primazia da mediação para que se estabeleça um diálogo profícuo com vistas à satisfação de interesses, em especial quando há ruptura de vínculos de afeto nas relações familiares.

\section{CONSIDERAÇÕES FINAIS}

Discutimos ao longo da pesquisa os novos desafios e mecanismos com vista a concretização de direitos; de modo que as atuais mudanças sociais e os novos desafios no campo do direito de família e sucessões têm contribuído ao rearranjo de um novo contexto, diferentemente daquela concepção pautada na autoridade ou no poder.

Os efeitos da cultura nas mudanças sociais, permite que as leis de direito material e processual passem por atuais processos interpretativos. Balizados por valores e princípios constitucionais com vistas à realização de novos direitos, a exemplo da equiparação da união homoafetiva à entidade familiar, inclusive com efeitos sucessórios, conforme decisão com repercussão geral pelo STF.

A síntese crítica que permeia a moderna ciência processual dá a forma e o contorno a esse novo sistema. As vivências sociais e políticas buscam pautar-se pelo respeito às diferenças, aos novos valores éticos e morais, o que transborda o limite espacial da família para uma nova conformação sob os influxos da internacionalização e transformação cultural.

Grande parte dos princípios que norteiam o direito processual se localiza nas fronteiras da epistemologia e da deontologia, entre as regras e os valores ético-moral e culturais; em outras palavras, entre os anseios, necessidades e contingências dos indivíduos, da família e da sociedade. Assim, confirma-se a hipótese de que as mudanças paradigmáticas apresentadas pelo novo CPC trouxeram importantes inovações no âmbito do direito de família e sucessões, especialmente, a partir da autocomposição, com foco na concretização de direitos.

Destacamos, a primazia da mediação nas relações familiares para o restabelecimento do diálogo dos envolvidos na lide com vistas à satisfação de seus interesses e, assim, se estabeleça uma cultura de paz. Portanto, o CPC/2015 apresenta o fortalecimento de novas instituições no Estado Democrático de Direito com vista à participação democrática e deliberativa do cidadão. A mediação tem papel relevante nesse contexto, posto que busca implementar a resolução de conflitos pelo diálogo com perspectivas de mudanças paradigmáticas no direito de família e sucessões e seus reflexos no contexto jurídico-social.

\section{REFERÊNCIAS}


BARBOSA, Águida Arruda. Construção dos fundamentos teóricos e práticos do código de família brasileiro. 2007. Tese (Doutorado em Direito Civil). Faculdade de Direito, USP, São Paulo, 2007.

BARROS, Renata Furtado de. DEROMA JÚNIOR (orgs.), Antônio Edson. O Estado

Democrático de Direito e a Evolução Jurídica: a quebra de paradigmas frente às necessidades sociais. Raleigh, Carolina do Norte, EUA: Lulu Publishing, 2012.

BAUMAN, Zygmunt. Comunidade: a busca por segurança no mundo atual. Rio de Janeiro, RJ: Jorge Zahar Ed., 2003.

BITTAR, Eduardo Carlos Bianca. Curso de filosofia do direito. São Paulo, SP: Atlas, 2005. BRASIL, Conselho Nacional de Justiça. Conciliação e Mediação. Brasília. 2016. Disponível em: 〈http://www.cnj.jus.br/programas-e-acoes/conciliacao-mediacao〉. Acesso em 22 de jul. 2016.

. Lei $\mathrm{n}^{\circ}$ 13.140, de 26 de junho de 2015. Portal da Legislação do Palácio do Planalto. Brasília. 2015. Disponível em: <http://www.planalto.gov.br/ccivil_03/_Ato20152018/2015/Lei/L13140.htm>. Acesso em 26 jul. 2016.

. Lei $\mathrm{n}^{\circ}$ 11.441, de 4 de janeiro de 2007. Portal da Legislação do Palácio do Planalto. Brasília. 2007. Disponível em: <http://www.cnj.jus.br/programas-eacoes/conciliacao-mediacao >. Acesso em 18 de mai. 2017.

BUENO, Cassio Scarpinella. Novo Código de Processo Civil Anotado; São Paulo, SP: Saraiva, 2015.

CÂMARA, Alexandre Freitas. O novo processo civil brasileiro. São Paulo, SP: Atlas, 2015. DIAS, Maria Berenice. Sociedade de afeto. Portal Jurídico Investidura, Florianópolis/SC, 15 Dez. 2004. Disponível em: investidura.com.br/biblioteca-juridica/artigos/direito-civil/2072sociedade-de-afeto. Acesso em 18 mai. 2017.

FERMENTÃO, Cleide Aparecida Gomes Rodrigues; FIGUEIREDO, Chrislayne Aparecida Pereira de; FIGUEIREDO, Elizio Lemes de. A eficácia horizontal dos direitos fundamentais e a constitucionalização do direito de família no Brasil. Actio Revista de Estudos Jurídicos. Faculdade Maringá, v.1. n. 25; jan/jun. 2015.

GAGLIANO, Pablo Stolze. Novo curso de direito civil, volume 6: Direito de família - As famílias em perspectiva constitucional. São Paulo, SP: Saraiva, 2012.

GIRARD, René; ANTONELLO, Pierpaolo; ROCHA, João Cezar de Castro. Evolução e 
conversão; São Paulo, SP: Realizações Editora, 2011.

HIRONAKA, Giselda Maria Fernandes Novaes; PEREIRA, Rodrigo da Cunha.

(Coordenadores). Direito das Sucessões. Belo Horizonte, MG: Del Rey, 2007.

IMHOF, Cristiano. Novo código de processo civil comentado. Rio de Janeiro, RJ: Lumen Juris, 2015.

KELSEN, Hans. Teoria Pura do Direito. São Paulo, SP: Martins Fontes, 2003.

LISBOA, Roberto Senise. Manual de direito civil, volume 5: direito de família e sucessões. São Paulo, SP: Saraiva, 2012.

MALUF, Adriana Caldas do Rego Freitas Dabus. Novas modalidades de família na pósmodernidade. 2010. Tese (Doutorado em Direito Civil). Faculdade de Direito, USP, São Paulo, 2010.

MILL, John Stuart. Ensaio sobre a liberdade. Coleção Grandes Obras do Pensamento Universal, volume 44; São Paulo, SP: Editora Escala, 2006.

MORAES, Alexandre de. Direito Constitucional. São Paulo, SP: Atlas, 2014.

MORIN, Edgar. Cultura de massas no século XX: neurose. Rio de Janeiro, RJ; Forense Universitária, 2007.

NOGUEIRA, Cristiane Santos de Souza et al. A mediação nos núcleos de práticas jurídicas: transformando mentalidades e prevenindo conflitos. SynThesis Revista Digital FAPAM, Pará de Minas, v.1, n.1, 1-17, out. 2009.

OLIVEIRA SOBRINHO, Afonso Soares de. A Pobreza na cidade de São Paulo como negação aos Direitos Humanos Fundamentais: a ética dialógica do Direito. Tese (Doutorado em Direito). Faculdade Autônoma de Direito, São Paulo, 2015.

PELIZZOLI, Marcelo (org.). Cultura de paz: restauração e direitos. Recife, PE: Ed. Universitária da UFPE; 2010.

ROCHA, Leonel Severo, et al. Tratamento do conflito jurídico familiar e o novo código de processo civil: contribuições dos conhecimentos disciplinares para os operadores do direito.

Revista Jurídica, 2016, 19.40: 111-134. Disponível em: <http://gorila.furb.br/ojs/index.php/juridica/article/view/5144/3215>.Acesso em 08. jun.2016. ROSENBERG, Marshall B. Comunicação não-violenta: técnicas para aprimorar relacionamentos pessoais e profissionais; São Paulo, SP: Ágora, 2006.

ROSENFIELD, Kathrin H. Sófocles e Antígona. Coleção Filosofia Passo-a-Passo, volume 9, Rio de Janeiro, RJ: Jorge Zahar Ed., 2002. 
SADEK, Maria Teresa (org.). O sistema de justiça. Rio de Janeiro, RJ: Centro Edelstein de Pesquisas Sociais, 2010.

SUPREMO TRIBUNAL FEDERAL. Julgamento afasta diferença entre cônjuge e companheiro para fim sucessório. Brasília. 2017. Disponível em: $<$ http://www.stf.jus.br/portal/cms/verNoticiaDetalhe.asp?idConteudo=342982>. Acesso em: 15. mai. 2017

TARTUCE, Fernanda. DELlORE, Luiz. MARIN, Marco Aurélio. Manual de Prática Civil. São Paulo, SP: Editora Método, 2014.

TARTUCE, Flávio. Direito Civil, 1: Lei de introdução e parte geral. Rio de Janeiro, RJ:

Forense; São Paulo, SP: Método, 2015.

VENOSA, Sílvio de Salvo. Código civil interpretado. São Paulo, SP: Atlas, 2011. , Direito civil: direito de família. São Paulo, SP: Atlas, 2013.

WARAT, Luis Alberto. Surfando na pororoca: o ofício do mediador. Florianópolis: Fundação Boiteux, 2004. p. 26.

XAVIER, Lucas Bittencourt. A família brasileira em face da história e do direito. Revista $\begin{array}{llll}\text { Científica } & \text { FAGOC-Jurídica, } & \text { 2016, } & \text { Disponível }\end{array}$ em:<http://revista.fagoc.br/index.php/juridico/article/view/55/29>. Acesso em 08. jun. 2016. ZEHR, Howard. Trocando as lentes: um novo foco sobre o crime e a justiça; São Paulo, SP: Palas Athena, 2008. 